\title{
Original
}

\section{Effects of chitosan oligosaccharides on intestinal oxidative stress and inflammation response in heat stressed rats}

\author{
Linlin WEI*, Yaxuan LI*, Qingqing CHANG, Guangzhen GUO and Ruixia LAN \\ College of Coastal Agriculture Science, Guangdong Ocean University, No. 1 Haida Road, Mazhang District, Zhanjiang \\ 524-088, Guangdong, P.R. China
}

\begin{abstract}
This study was to verify the effects of chitosan oligosaccharides (COS) on intestinal integrity, oxidative status, and inflammatory response in a heat-stressed rat model. A total of 24 male Sprague Dawley rats were randomly divided into 3 treatment: CON, the control group; HS, the heat stress group; HSC, the heat stress group with $200 \mathrm{mg} / \mathrm{kg}$ COS. Rats in the HS and HSC group exposed to a cyclical heat stress for 7 consecutive days. The CON and HS group provided basal diet, and the HSC group provided the same diet with $200 \mathrm{mg} / \mathrm{kg}$ COS. Compared with the HS group, rats in the HSC group had lower serum diamine oxidase and D-lactate acid level, higher villus height of jejunum and ileum, lower malondialdehyde (MDA) content in duodenum, jejunum, and ileum mucosa, higher glutathione peroxidase (GSH-Px), catalase (CAT) and total antioxidant capacity (T-AOC) activity in duodenum mucosa, higher T-AOC activity in jejunum mucosa, and higher glutathione (GSH) level in ileum mucosa. Compared with the HS group, rats in the HSC group had higher interleukin-10 (IL-10) level, but lower tumor necrosis factor- $\alpha$ (TNF- $\alpha$ ) level in duodenum, jejunum, and ileum mucosa. These results indicated that COS may alleviate intestinal damage under heat stress condition, probably by modulating intestinal inflammatory response and oxidative status. Key words: chitosan oligosaccharides, heat stress, inflammation response, intestine, oxidative status
\end{abstract}

\section{Introduction}

Heat stress had detrimental effects on human beings and animal health, resulting in great economic losses in public health and animal production. In United States, there was an average estimated 1,500 heat-related deaths every summer [1]. In 2003, there were 50,000 Europeans that died due to heat wave $[2,3]$. In 2006, heat wave led to the death of over 700,000 poultry and 25,000 cattle in California [4]. On average, heat stress reduced annal economic losses to 1.7 billion dollars in United States livestock industry, 897 million in dairy industry, 369 million in beef industry, 299 million in swine industry, and 128 million in poultry industry, respectively [5]. Unfortunately, global warming would further accentuate heat stress-related problems, especially in subtropical and tropical regions [6]. The intestinal tract was sensitive to heat stress, and the intestinal dysfunction was regarded as the early symptom of heat stress [7]. Previous studies provided evidence that heat stress results in intestinal dysfunction and damage by changing digestive and absorption ability, intestinal morphology and barrier function [8-12]. The crucial role of intestine is to absorb nutrient, as well as provides an innate defense barrier to resist the pathogens invade [5]. When heat stress-induced intestinal injury, the increase of intestinal permeability rose the translocation of pathogen bacterial, causing intestinal mucosal inflammatory response. Meanwhile, heat stress dramatically increased the level of reactive oxygen species (ROS) and resulted in oxidative stress [13]. Both oxidative stress and inflammation can damage intestinal function. Intestinal damage has

(Received 15 June 2020 / Accepted 12 August 2020 / Published online in J-STAGE 11 September 2020)

Corresponding author: R. Lan.e-mail:Lanrx@gdou.edu.cn

*These authors contributed equally to this work.

This is an open-access article distributed under the terms of the Creative Commons Attribution Non-Commercial No Derivatives (by-nc-nd) License <http://creativecommons.org/licenses/by-nc-nd/4.0/>

(C)2021 Japanese Association for Laboratory Animal Science 
vital economics impact for produces, therefore, intestinal health is widely concerned to maintain animal performance, welfare, and health [14]. There were growing attentions for nutritional intervention to improve intestinal health, especially, under heat stress condition [6]. Recently, special attention was paid to prebiotic. It has been reported that cello-oligosaccharide, galacto-oligosaccharide, and mannan oligosaccharide could effectively alleviate heat stress-induced intestinal injury and oxidative stress $[8,11,15]$. Chitosan oligosaccharides (COS), one of the functional oligosaccharides, was enzymatic or chemical hydrolysis from chitosan, the second most abundant polysaccharide in nature [16]. Former studies reported the beneficial effects of COS on growth performance $[17,18]$, intestinal morphology [19], intestinal barrier function [19], anti-bacterial capacity [20, 21] free radical scavenging capacity [22], and particularly the anti-oxidant $[20,23]$ and anti-inflammatory capacity [23-27]. COS had specific immunomodulatory effects, which can polarize the cytokine balance toward TH1 cytokines, decrease the production of the inflammatory cytokines tumor necrosis factor- $\alpha(T N F-\alpha)$ and interleukin-6 (IL-6), down-regulate toll-like receptor-4 (TLR4) and CD44 receptor expression, and inhibit T cell proliferation of weaning pigs [28]. However, the effect of COS on intestinal integrity, oxidative status and inflammation response under heat stress condition has not been reported previously, we hypothesized that dietary COS supplementation may improve intestinal integrity by alleviating oxidative stress and inflammation response. Therefore, the purpose of this study was to verify the hypothesis by evaluating the effects of dietary COS on intestinal integrity, oxidative status, and inflammatory response in a heat stress rat model.

\section{Materials and Methods}

\section{Experimental design and dietary treatments}

The experimental procedures were approved by the Animal Care and Use Committee of Guangdong Ocean University (SYXK-2018-0147). A total of 24 8-week old male Sprague Dawley rats (body weight 202.36 \pm 8.31 g) was purchased from Beijing Administration Office of Laboratory Animal (Beijing, China). The rats were individually housed, free accessed to standard chow diet and tap water, kept under the condition of controlled temperature $\left(24 \pm 1^{\circ} \mathrm{C}\right)$ and humidity $(55 \pm 5 \%)$, with a 12-h light-dark cycle. After a week of acclimatization, the 24 rats were randomly divided into 3 treatment: $\mathrm{CON}$, the control group; HS, the heat stress group; HSC, the heat stress group with $200 \mathrm{mg} / \mathrm{kg}$ COS supplementation. The heat stress treatment and COS supplementation dose were set up according to the previous study [29]. Briefly, rats in the HS and HSC group were exposed to cyclical heat stress conditions $\left(35^{\circ} \mathrm{C}\right.$ from $10: 00$ to $14: 00$ and $24^{\circ} \mathrm{C}$ from $14: 00$ to $\left.10: 00\right)$ for 7 consecutive days, and rats in the $\mathrm{CON}$ group was maintained at $24^{\circ} \mathrm{C}$. The initial and final body weight were measured, and the average daily gain was calculated during the experiment. Rats in the CON and HS group provided basal diet, while those in the HSC group provided the same diet with 200 $\mathrm{mg} / \mathrm{kg}$ COS supplementation. The COS was purchased from Jiangsu Xinrui Biotechnology Co., Ltd. (HPLC purity $95 \%$, deacetylation degree over $95 \%$ and average molecular weight below $32 \mathrm{kDa}$ ).

\section{Sample collection}

On the 7 th day of the experiment, after heat stress treatment and body wight checking, rats were anesthetized and sacrificed. The blood sample were collected through eyeballs and centrifuged at 3,000 $\mathrm{g}$ for $15 \mathrm{~min}$ at $4^{\circ} \mathrm{C}$ to obtain serum. The serum samples stored at $-20^{\circ} \mathrm{C}$ until further analysis. The duodenum, jejunum and ileum samples collection were following the method described by Lu et al. [30]. The samples from the duodenum, jejunum, and ileum were divided into two parts: about 2-centimeter at the midpoint of duodenum, jejunum and ileum were fixed in $10 \%$ buffered formalin for morphology examination, and the rest parts were opened longitudinally and flushed with ice-cold phosphatebuffered saline (PBS). Mucosa of each segment sample was collected using a sterile glass microscope slide, snap frozen in liquid nitrogen, and stored at $-80^{\circ} \mathrm{C}$ for further analysis.

\section{Serum diamine oxidase (DAO) and D-lactate acid (D-LA) determination}

Serum diamine oxidase activity and D-lactate acid concentration were measured with commercial kits (Nanjing Jiancheng Institute of Bioengineering, Nanjing, China) according to the manufacturers' instruction.

\section{Intestinal morphology examination}

Intestinal segments were fixed in $10 \%$ buffered formalin for $48 \mathrm{~h}$ at room temperature and subsequently dehydrated through a graded ethanol series, then cleared with xylene and finally embedded in paraffin for histological examination. For the histological analyses to measure villus height (VH), crypt depth (CD), serial tissue sections of $4 \mu \mathrm{m}$ were cut and mounted 4 sections per side. The sections were deparaffinized, rehydrated, rinsed in distilled water, stained with hematoxylin and eosin, dehydrated, and mounted. The gastrointestinal morphometric variables evaluated $\mathrm{VH}, \mathrm{CD}$, and the ratio 
of villus height to crypt depth (VH:CD). Morphological parameters were measured using Image Pro Plus 6.0 software (Media Cybernetics, Silver Spring, MD). Each sample was subjected to 6 replicate measurements for each variable studied, then averaged to generate a mean value. The VH was measured from the top of the villus to the top of the lamina propria. CD was measured from the base upward to the region of transition between the crypt and villus.

\section{Determination of intestinal mucosal oxidative status and cytokines}

About $1 \mathrm{~g}$ of duodenum, jejunum, and ileum mucosa samples were homogenized at a ratio of 1: 9 (weight/ volume) with ice-cold PBS. Homogenate was centrifuged at 3,000 $\mathrm{g}$ for $15 \mathrm{~min}$ at $4^{\circ} \mathrm{C}$ to obtain supernatant, and immediately conduct the analysis. The protein concentration of the supernatant was determined by the Bradford method [31]. The activity of superoxide dismutase (SOD), glutathione peroxidase (GSH-Px), catalase (CAT), and total antioxidant capacity (T-AOC), the malondialdehyde (MDA), glutathione (GSH), interleukin-1 $\beta$ (IL-1 $\beta$ ), IL-6, IL-10, and tumor necrosis factor- $\alpha$ (TNF- $\alpha$ ) level were measured with corresponding assay kits (Nanjing Jiancheng Bioengineering Institute, Nanjing, China) following the manufacturer's instruction.

\section{Statistical analysis}

The individual rat was used as the experiment unit and all data was analyzed with SAS 2003 (v. 9.1, SAS Institute Inc., Cary, NC, USA). All data was analyzed using one-way analysis of variance followed by Duncan's multiple range test to analyze differences among treatments. Differences were considered significant at $P<0.05$.

\section{Results}

\section{Growth performance and Intestinal morphology}

The initial and final body weight, and average daily gain were presented in Table 1. No significant differences were observed in initial and final body weight among treatments. Compared with the control group fed the basal diet, heat stress decreased average daily gain $(P<0.05)$. Compared with the heat stress group, dietary COS supplementation increased average daily gain under heat stress condition $(P<0.05)$.

Figure 1 and Table 2 showed intestinal morphology measurements. Compared with the control group fed the basal diet, heat stress decreased villus height of duodenum, jejunum, as well as ileum, and villus height to crypt depth ratio of ileum $(P<0.05)$. Compared with the heat stress group, dietary COS supplementation increased villus height of jejunum and ileum under heat stress condition $(P<0.05)$.

\section{Serum DAO activity and D-LA content}

The serum DAO activity and D-LA level were useful markers for evaluating the intestinal integrity. As shown in Fig. 2, compared with the control group fed the basal diet, heat stress increased serum DAO activity and D-LA content $(P<0.05)$. Compared with the heat stress group, dietary COS supplementation decreased serum DAO activity and D-LA content under heat stress condition $(P<0.05)$.

\section{Intestinal oxidant status}

Intestinal barrier function, which was influenced by intestinal oxidant status, was demonstrated in Fig. 3. Compared with the control group fed the basal diet, heat stress increased duodenum, jejunum and ileum mucosal MDA content, decreased duodenum mucosal GSH-Px, CAT, and T-AOC activity, jejunum mucosal CAT, GSH, and T-AOC activity, as well as ileum mucosal GSH activity $(P<0.05)$. As expected, compared with the heat stress group, dietary COS supplementation decreased duodenum, jejunum and ileum mucosal MDA content, increased duodenum mucosal GSH-Px, CAT, and T-AOC activity, jejunum mucosal T-AOC activity, as well as ileum mucosal GSH activity under heat stress condition $(P<0.05)$. No significant differences were observed in duodenum mucosal SOD or GSH activity, jejunum mucosal SOD or GSH-Px activity, as well as ileum mucosal SOD, GSH-Px, CAT, or T-AOC activity among treatments.

Table 1. Effects of chitosan oligosaccharides on body weight of Sprague Dawley rats under heat stress

\begin{tabular}{lccccc}
\hline \multicolumn{1}{c}{ Item $^{1}$} & CON & HS & HSC & SEM & $P$-value \\
\hline Initinal body weight, g & 202.49 & 203.00 & 201.58 & 3.30 & 0.3309 \\
Final body weight, g & 288.50 & 276.67 & 283.50 & 3.72 & 0.1008 \\
Average daily gain, g & $12.29^{\mathrm{a}}$ & $10.52^{\mathrm{b}}$ & $11.70^{\mathrm{a}}$ & 0.26 & 0.0060 \\
\hline
\end{tabular}

${ }^{1} \mathrm{CON}$ group, basal diet; HS group, basal diet and heat stress; HSC group, basal diet with $200 \mathrm{mg} / \mathrm{kg}$ COS and heat stress. ${ }^{\mathrm{a}, \mathrm{b}}$ Different superscripts within the same row present significance $(P<0.05)$. 


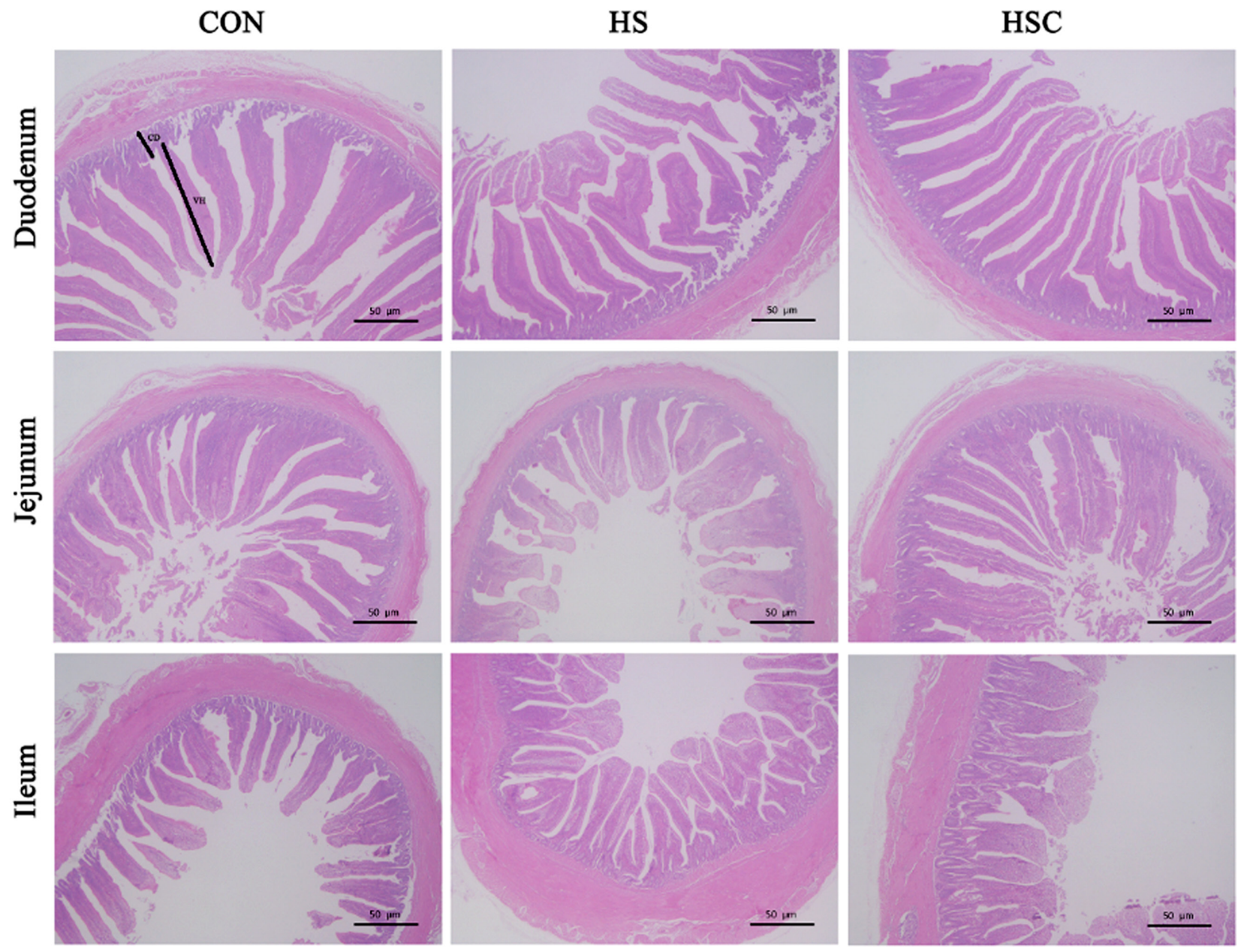

Fig. 1. Effects of chitosan oligosaccharides (COS) on the intestinal morphology in Sprague Dawley rats under heat stress. CON group, control group fed the basal diet; HS group, basal diet and heat stress; HSC group, basal diet with $200 \mathrm{mg} / \mathrm{kg}$ COS and heat stress; $\mathrm{VH}$, villus height; CD, crypt depth. Hematoxylin and eosin staining with magnification $\times 100$. Bars represent $50 \mu \mathrm{m}$.

Table 2. Effects of chitosan oligosaccharides on intestinal mucosal morphology of Sprague Dawley rats under heat stress

\begin{tabular}{lccccc}
\hline Item $^{1}$ & CON & HS & HSC & SEM & $P$-value \\
\hline Duodenum & & & & & \\
$\quad$ Villus height $(\mu \mathrm{m})$ & $276.04^{\mathrm{a}}$ & $234.90^{\mathrm{b}}$ & $255.38^{\mathrm{ab}}$ & 10.84 & 0.0664 \\
Crypt depth $(\mu \mathrm{m})$ & 103.82 & 90.67 & 96.41 & 8.55 & 0.5699 \\
$\quad$ Villus height:crypt depth & 2.79 & 2.68 & 2.68 & 0.27 & 0.9457 \\
Jejunum & & & & & \\
$\quad$ Villus height $(\mu \mathrm{m})$ & $214.73^{\mathrm{a}}$ & $152.59^{\mathrm{b}}$ & $195.96^{\mathrm{a}}$ & 12.85 & 0.0181 \\
Crypt depth $(\mu \mathrm{m})$ & 81.68 & 71.13 & 65.19 & 9.34 & 0.4761 \\
Villus height:crypt depth & 2.72 & 2.38 & 3.13 & 0.34 & 0.3329 \\
Ileum & & & & & \\
Villus height $(\mu \mathrm{m})$ & $176.83^{\mathrm{a}}$ & $111.56^{\mathrm{b}}$ & $152.19^{\mathrm{a}}$ & 8.15 & 0.0007 \\
Crypt depth $(\mu \mathrm{m})$ & 59.35 & 47.85 & 62.47 & 5.91 & 0.2324 \\
Villus height:crypt depth & $3.09^{\mathrm{a}}$ & $2.44^{\mathrm{b}}$ & $2.44^{\mathrm{b}}$ & 0.17 & 0.0306 \\
\hline
\end{tabular}

${ }^{1} \mathrm{CON}$ group, basal diet; HS group, basal diet and heat stress; HSC group, basal diet with 200 $\mathrm{mg} / \mathrm{kg}$ COS and heat stress. ${ }^{\mathrm{a}, \mathrm{b}}$ Different superscripts within the same row present significance $(P<0.05)$.

\section{Intestinal inflammatory cytokines}

As shown in Fig. 4, compared with the control group fed the basal diet, heat stress increased duodenum mucosal IL- $1 \beta$ and TNF- $\alpha$ level, jejunum and ileum muco- sal TNF- $\alpha$ level, decreased duodenum, jejunum, and ileum mucosal IL-10 level $(P<0.05)$. As expected, compared with the heat stress group, dietary COS supplementation decreased duodenum, jejunum, and ileum 

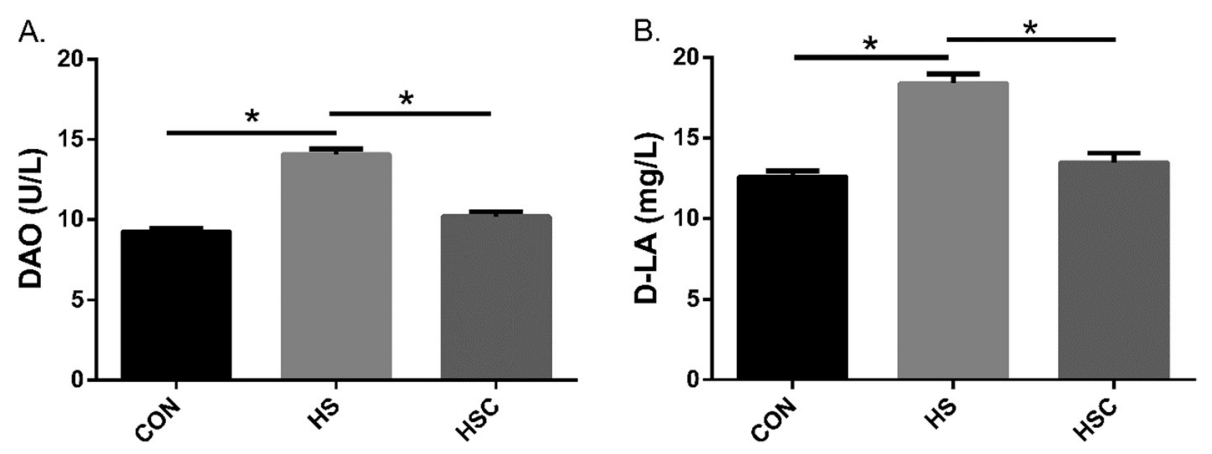

Fig. 2. Effects of chitosan oligosaccharides (COS) on serum diamine oxidase (DAO) and D-lactate acid (D-LA) in Sprague Dawley rats under heat stress. CON group, control group fed the basal diet; HS group, basal diet and heat stress; HSC group, basal diet with $200 \mathrm{mg} / \mathrm{kg}$ COS and heat stress. Values are mean \pm SE. $* P<0.05$.

mucosal TNF- $\alpha$ level, increased $(P<0.05)$ duodenum, jejunum, and ileum mucosal IL-10 level under the heat stress condition $(P<0.05)$. No significant differences were observed in duodenum mucosal IL-6 level, jejunum and ileum mucosal IL-1 $\beta$ or IL-6 level among treatments.

\section{Discussion}

Heat stress, known to induce oxidative stress and inflammation response, and the detrimental effects of heat stress on intestinal function has been widely concerned $[7,8,11,32-34]$. Intestinal mucosal permeability directly reflected the gut health. To evaluate intestinal health, the indices of gut morphology and serum DAO and D-LA level were assessed. Previous studies indicated that heat stress resulted in a shorter $\mathrm{VH}$, deeper $\mathrm{CD}$, and a lower VH:CD ratio $[35,36]$. Similarly, in this study, heat stress decreased $\mathrm{VH}$ of duodenum, jejunum and ileum, as well as ileum VH:CD ratio. However, dietary COS supplementation increased $\mathrm{VH}$ of jejunum and ileum, suggesting that COS may prevent the jejunum and ileum from epithelial cell necrosis and villous atrophy. In consistent with our results, Liu et al. (2008) indicated that dietary COS supplementation increased $\mathrm{VH}$ in the jejunum and ileum of weaning pigs [35]. However, Li et al. (2019) indicated that dietary COS supplementation increased $\mathrm{VH}$ in the duodenum of broilers [19]. These differences may relate to the species, adding dosage, deacetylation level, polymerization degree, and purity of COS. As N-acetylglucosamine is the functional component of COS, former studies indicated that $\mathrm{N}$-acetylglucosamine may bind to gut microflora and interfere with their adhesion in gut [29]. Mourao et al. (2006) demonstrated that there was a correlation with increased VH in the ileum and decreased microflora [37]. Dietary COS supplementation may create a convenient intestinal microflora environment, which is the possible reason to explanation the increased $\mathrm{VH}$ in the jejunum and ileum with COS supplementation in this study.

The increased serum DAO and D-LA level were the indicators of intestinal dysfunction [38]. In parallel with the aforementioned findings, serum DAO and D-LA level were significantly decreased with dietary COS supplementation. Similarly, Li et al. (2019) indicated that dietary COS supplementation decreased serum DAO activity [19]. Based on these results, dietary COS supplementation may be a promising way to alleviate the intestinal barrier damage under heat stress condition.

ROS played a vital role in intestinal dysfunction and injury. Under heat stress condition, the ROS level enhanced dramatically [39]. The imbalance between ROS and the available anti-oxidants culminated oxidative stress. COS was known to have anti-oxidant capacity in vitro and in vivo [40]. Dietary COS supplementation could alleviate heat stress-induced oxidative stress in liver, spleen, and kidney of Sprague Dawley rats [26]. In this study, we observed that heat stress-induced higher duodenum, jejunum and ileum mucosal MDA content, decreased duodenum mucosal GSH-Px, CAT, and TAOC activity, jejunum mucosal CAT, GSH, and T-AOC activity, and ileum mucosal GSH activity. MDA was served as the marker of oxidative stress, as expected, dietary COS supplementation decreased duodenum, jejunum, and ileum mucosal MDA content, increased duodenum mucosal GSH-Px, CAT, and T-AOC activity, jejunum mucosal T-AOC activity, and ileum mucosal GSH activity. The decreased MDA content and the increased activity of GSH-Px, CAT, GSH, and T-AOC in small intestine reflected the enhanced anti-oxidant capacity [41]. These results suggested that dietary COS supplementation may alleviate heat stress-induced small intestine mucosal oxidative stress.

Heat stress impaired the intestinal barrier function, promoting luminal antigens translation, and finally caus- 

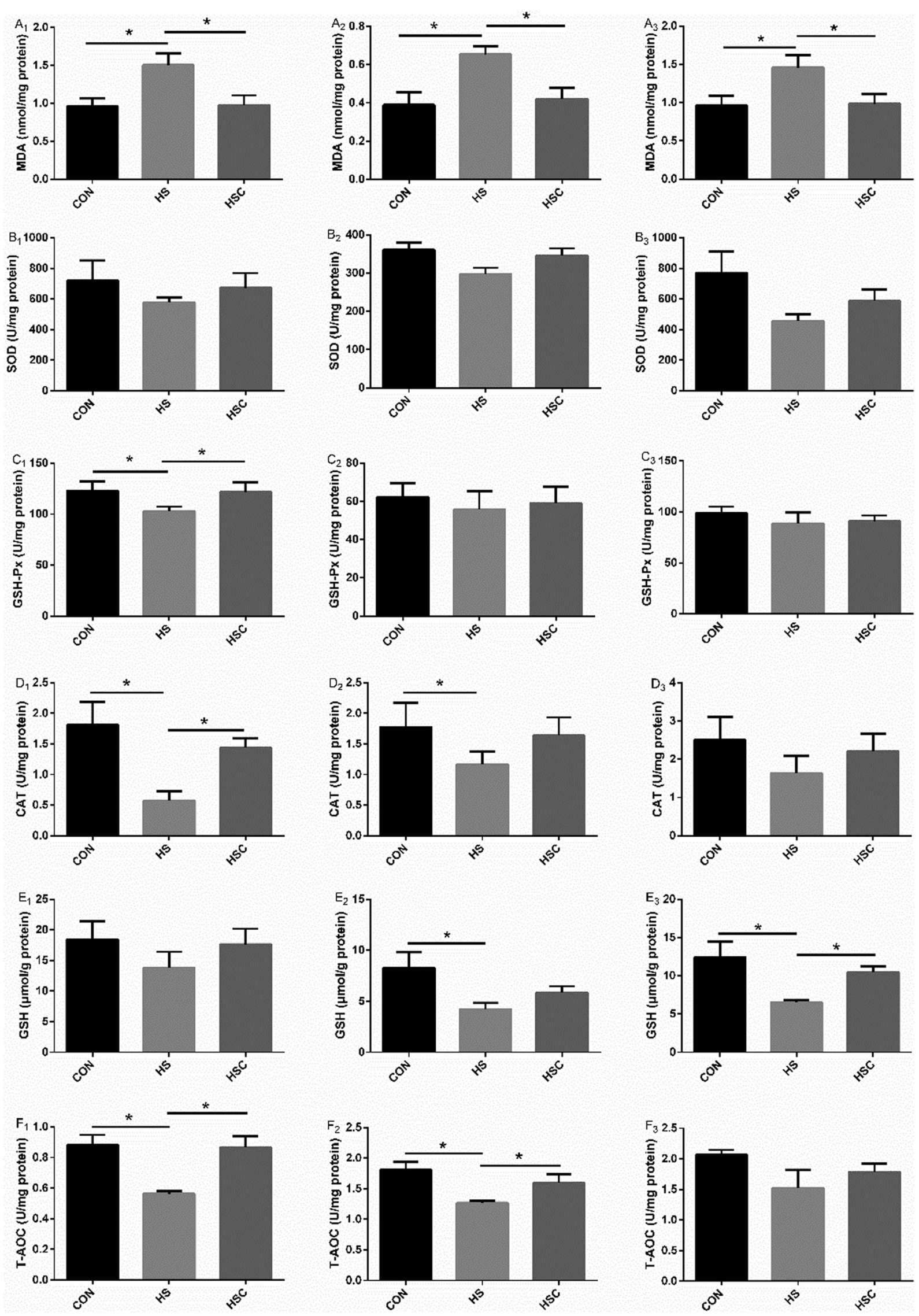

Fig. 3. Effects of chitosan oligosaccharides (COS) on oxidant status of small intestine in Sprague Dawley rats under heat stress. CON group, control group fed the basal diet; HS group, basal diet and heat stress; HSC group, basal diet with $200 \mathrm{mg} / \mathrm{kg}$ COS and heat stress. $A_{1}-F_{1}$, duodenum; $A_{2}-F_{2}$, jejunum; $A_{3}-F_{3}$, ileum; MDA, malondialdehyde; SOD, superoxide dismutase; GSH-Px, glutathione peroxidase; CAT, catalase; GSH, glutathione; T-AOC, total anti-oxidant capacity. Values are mean $\pm \mathrm{SE}$. ${ }^{*} P<0.05$. 

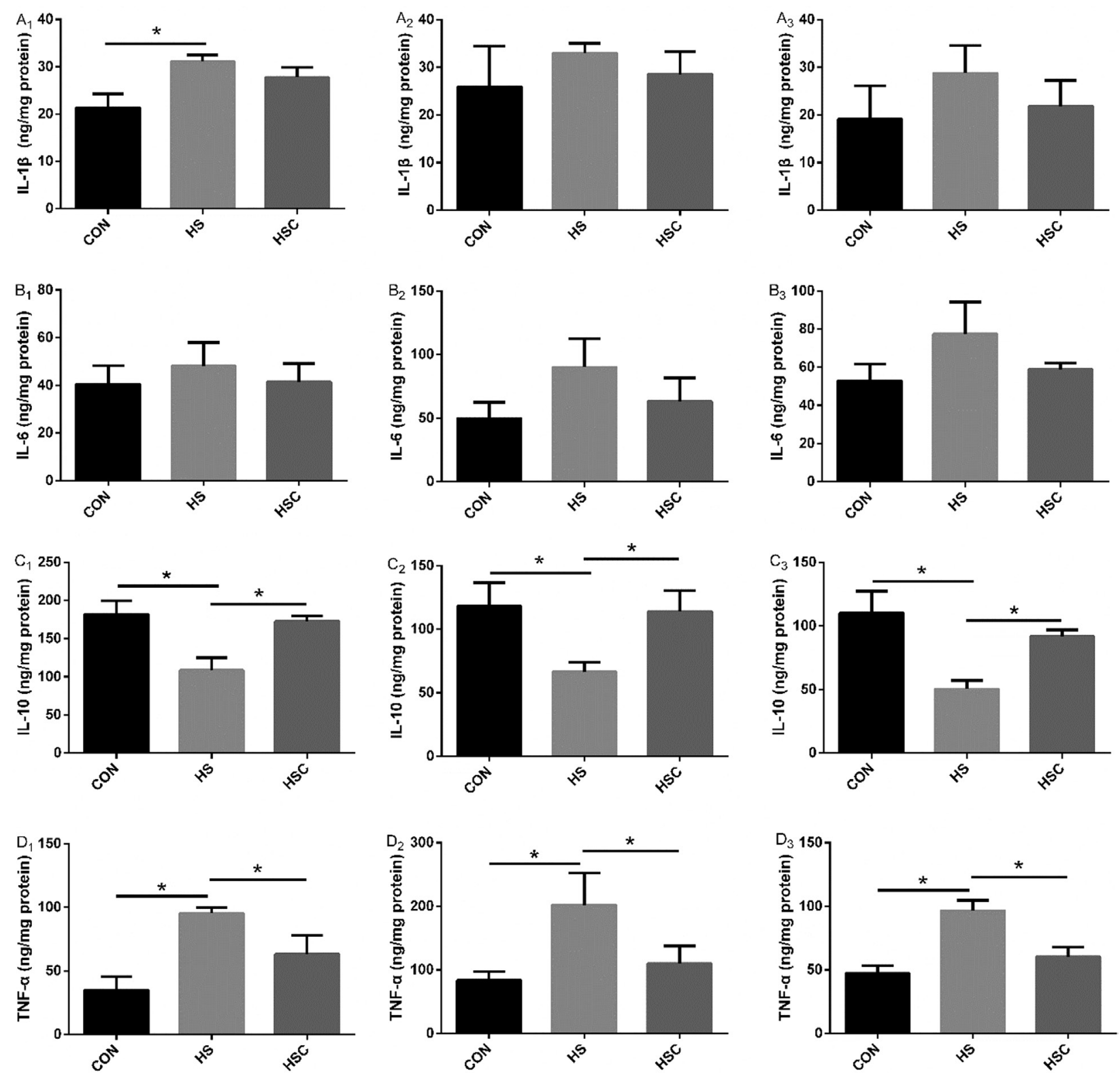

Fig. 4. Effects of chitosan oligosaccharides (COS) on inflammatory cytokines of small intestine in Sprague Dawley rats under heat stress. CON group, control group fed the basal diet; HS group, basal diet and heat stress; HSC group, basal diet with $200 \mathrm{mg} /$ $\mathrm{kg} \operatorname{COS}$ and heat stress. $A_{1}-D_{1}$, duodenum; $A_{2}-D_{2}$, jejunum; $A_{3}-D_{3}$, ileum; IL-1 $\beta$, interleukin- $1 \beta$; IL-6, interleukin-6; IL-10, interleukin-10; TNF- $\alpha$, tumor necrosis factor- $\alpha$. Values are mean \pm SE. $* P<0.05$.

ing systemic and mucosal inflammatory response. Activation of the corresponding receptors resulted in the inflammatory cytokines production and tissue injury. TLR4 was an important innate immune receptor, which can control inflammation by inhibition NF- $\kappa \mathrm{B}$ signaling pathway [42]. TLR4 activated NF- $\kappa B$ signaling pathway, which lead to the following induction of NF- $\kappa B$ signaling pathway genes, such as $I L-1 \beta, I L-6, I L-10$ and $T N F-\alpha$ [43]. The intestinal barrier integrity could be affected by the imbalance between anti- and pro-inflammatory cytokines $[44,45]$. Former studies indicated that the intestinal barrier disruption accompanied with increased IL-6 and IL-8 level [46, 47]. Song et al. (2017) indicated that heat stress increased IL- $1 \beta$ level, as well as $I L-1 \beta$ and IL-6 mRNA abundances in jejunum and ileum [33]. In this study, heat stress decreased duodenum, jejunum, and ileum mucosal anti-inflammatory IL-10 level, increased duodenum mucosal pro-inflammatory IL- $1 \beta$ and TNF- $\alpha$ level, jejunum and ileum mucosal pro-inflammatory TNF- $\alpha$ level. These results suggested that heat stressinduced intestinal inflammatory response. It has been reported that dietary COS supplementation could enhance immune response by modulating the production of inflammatory cytokines [21,27]. As expected, dietary COS supplementation increased duodenum, jejunum, and ileum mucosal IL-10 level, as well as decreased 
TNF- $\alpha$ level, these results suggested that COS had beneficial effects on alleviating intestinal inflammatory response under heat stress condition. After COS adheres to intestinal mucosa, the immune system could recognize its amine part and initiate immunomodulation system, which may help to prevent intestinal inflammation. Therefore, the positive effects of COS on intestinal function may associated with its anti-inflammatory capacity [43], resulted in higher anti-inflammatory cytokines level, and lower pro-inflammatory cytokines.

\section{Conclusions}

In conclusion, heat stress impaired intestinal morphology, increased intestinal permeability, impaired intestinal anti-oxidant status, and enhanced inflammatory response. Nevertheless, dietary COS supplementation had beneficial effects on intestinal morphology, permeability, antioxidant capacity and inflammatory response under heat stress condition. These results suggested that dietary COS could alleviate heat stress-induced intestinal oxidative stress and inflammatory response.

\section{Acknowledgment}

This research was funded by program for scientific research start-up funds of Guangdong Ocean University (101402/R18005), College Students' Innovative Entrepreneurial Training Plan Program (S202010566030), and Key Platform Project of Innovation Strong School Engineering by Department of Education of Guangdong Province (2018302).

\section{References}

1. Rhoads RP, Baumgard LH, Suagee JK, Sanders SR. Nutritional interventions to alleviate the negative consequences of heat stress. Adv Nutr. 2013; 4: 267-276. [Medline] [CrossRef]

2. Kosatsky T. The 2003 European heat waves. Euro Surveill. 2005; 10: 3-4. [Medline] [CrossRef]

3. Patz JA, Campbell-Lendrum D, Holloway T, Foley JA. Impact of regional climate change on human health. Nature. 2005; 438: 310-317. [Medline] [CrossRef]

4. Nienaber JA, Hahn GL. Livestock production system management responses to thermal challenges. Int J Biometeorol. 2007; 52: 149-157. [Medline] [CrossRef]

5. Turner JR. Intestinal mucosal barrier function in health and disease. Nat Rev Immunol. 2009; 9: 799-809. [Medline] [CrossRef]

6. Renaudeau D, Collin A, Yahav S, de Basilio V, Gourdine JL, Collier RJ. Adaptation to hot climate and strategies to alleviate heat stress in livestock production. Animal. 2012; 6: 707-728. [Medline] [CrossRef]

7. Cheng K, Song Z, Li S, Yan E, Zhang H, Zhang L, et al. Effects of resveratrol on intestinal oxidative status and inflammation in heat-stressed rats. J Therm Biol. 2019; 85: 102415. [Medline] [CrossRef]

8. Cheng YF, Chen YP, Chen R, Su Y, Zhang RQ, He QF, et al. Dietary mannan oligosaccharide ameliorates cyclic heat stress-induced damages on intestinal oxidative status and barrier integrity of broilers. Poult Sci. 2019; 98: 4767-4776. [Medline] [CrossRef]

9. Liu G, Zhu H, Ma T, Yan Z, Zhang Y, Geng Y, et al. Effect of chronic cyclic heat stress on the intestinal morphology, oxidative status and cecal bacterial communities in broilers. $\mathrm{J}$ Therm Biol. 2020; 91: 102619. [Medline] [CrossRef]

10. Song ZH, Cheng K, Zheng XC, Ahmad H, Zhang LL, Wang T. Effects of dietary supplementation with enzymatically treated Artemisia annua on growth performance, intestinal morphology, digestive enzyme activities, immunity, and antioxidant capacity of heat-stressed broilers. Poult Sci. 2018; 97: 430437. [Medline] [CrossRef]

11. Song J, Jiao LF, Xiao K, Luan Z, Hu C, Shi B, et al. Cello-oligosaccharide ameliorates heat stress-induced impairment of intestinal microflora, morphology and barrier integrity in broilers. Anim Feed Sci Technol. 2013; 185: 175-181. [CrossRef]

12. Yi D, Hou Y, Tan L, Liao M, Xie J, Wang L, et al. N-acetylcysteine improves the growth performance and intestinal function in the heat-stressed broilers. Anim Feed Sci Technol. 2016; 220: 83-92. [CrossRef]

13. Yang L, Tan GY, Fu YQ, Feng JH, Zhang MH. Effects of acute heat stress and subsequent stress removal on function of hepatic mitochondrial respiration, ROS production and lipid peroxidation in broiler chickens. Comp Biochem Physiol C Toxicol Pharmacol. 2010; 151: 204-208. [Medline] [CrossRef]

14. Roberts T, Wilson JS, Guthrie A, Cookson K, Vancraeynest D, Schaeffer J, et al. New issues and science in broiler chicken intestinal health: intestinal microbial composition, shifts, and impacts. Worlds Poult Sci J. 2015; 71: 259-270. [CrossRef]

15. Varasteh S, Braber S, Akbari P, Garssen J, Fink-Gremmels J. Differences in susceptibility to heat stress along the chicken intestine and the protective effects of galacto-oligosaccharides. PLoS One. 2015; 10: e0138975. [Medline] [CrossRef]

16. Zou P, Yang X, Wang J, Li Y, Yu H, Zhang Y, et al. Advances in characterisation and biological activities of chitosan and chitosan oligosaccharides. Food Chem. 2016; 190: 1174-1181. [Medline] [CrossRef]

17. Li XJ, Piao XS, Kim SW, Liu P, Wang L, Shen YB, et al. Effects of chito-oligosaccharide supplementation on performance, nutrient digestibility, and serum composition in broiler chickens. Poult Sci. 2007; 86: 1107-1114. [Medline] [CrossRef]

18. Zhou TX, Chen YJ, Yoo JS, Huang Y, Lee JH, Jang HD, et al. Effects of chitooligosaccharide supplementation on performance, blood characteristics, relative organ weight, and meat quality in broiler chickens. Poult Sci. 2009; 88: 593-600. [Medline] [CrossRef]

19. Li J, Cheng Y, Chen Y, Qu H, Zhao Y, Wen C, et al. Dietary chitooligosaccharide inclusion as an alternative to antibiotics improves intestinal morphology, barrier function, antioxidant capacity, and immunity of broilers at early age. Animals (Basel). 2019; 9: 493-505. [Medline] [CrossRef]

20. Li X, Ding X, Peng X, Chi X, Cui H, Zuo Z, et al. Effect of chitosan oligosaccharides on antioxidant function, lymphocyte cycle and apoptosis in ileum mucosa of broiler. Kafkas Univ Vet Fak Derg. 2017; 23: 571-577.

21. Wan J, Jiang F, Xu Q, Chen D, Yu B, Huang Z, et al. New insights into the role of chitosan oligosaccharide in enhancing growth performance, antioxidant capacity, immunity and intestinal development of weaned pigs. RSC Advances. 2017; 7: 9669-9679. [CrossRef]

22. Je JY, Park PJ, Kim SK. Free radical scavenging properties of hetero-chitooligosaccharides using an ESR spectroscopy. Food Chem Toxicol. 2004; 42: 381-387. [Medline] [CrossRef]

23. Lan R, Chang Q, An L, Zhao Z. Dietary Supplementation with 
chitosan oligosaccharides alleviates oxidative stress in rats challenged with hydrogen peroxide. Animals (Basel). 2019; 10: 55-67. [Medline] [CrossRef]

24. Fernandes JC, Spindola H, de Sousa V, Santos-Silva A, Pintado ME, Malcata FX, et al. Anti-inflammatory activity of chitooligosaccharides in vivo. Mar Drugs. 2010; 8: 1763-1768. [Medline] [CrossRef]

25. Hyung JH, Ahn CB, Il Kim B, Kim K, Je JY. Involvement of Nrf2-mediated heme oxygenase-1 expression in anti-inflammatory action of chitosan oligosaccharides through MAPK activation in murine macrophages. Eur J Pharmacol. 2016; 793: 43-48. [Medline] [CrossRef]

26. Lan R, Li S, Chang Q, Zhao Z. Chitosan oligosaccharides protect sprague dawley rats from cyclic heat stress by attenuation of oxidative and inflammation stress. Animals (Basel). 2019; 9: 1074-1086. [Medline] [CrossRef]

27. Xiong X, Yang HS, Wang XC, Hu Q, Liu CX, Wu X, et al. Effect of low dosage of chito-oligosaccharide supplementation on intestinal morphology, immune response, antioxidant capacity, and barrier function in weaned piglets. J Anim Sci. 2015; 93: 1089-1097. [Medline] [CrossRef]

28. Xiao D, Wang Y, Liu G, He J, Qiu W, Hu X, et al. Effects of chitosan on intestinal inflammation in weaned pigs challenged by enterotoxigenic Escherichia coli. PLoS One. 2014; 9: e104192. [Medline] [CrossRef]

29. Kim S, Rajapakse N. Enzymatic production and biological activities of chitosan oligosaccharides (COS): A review. Carbohydr Polym. 2005; 62: 357-368. [CrossRef]

30. Lu A, Wang H, Hou X, Li H, Cheng G, Wang N, et al. Microarray analysis of gene expression profiles of rat small intestine in response to heat stress. J Biomol Screen. 2011; 16: 655-667. [Medline] [CrossRef]

31. Bradford MM. A rapid and sensitive method for the quantitation of microgram quantities of protein utilizing the principle of protein-dye binding. Anal Biochem. 1976; 72: 248-254. [Medline] [CrossRef]

32. Jang IS, Ko YH, Moon YS, Sohn SH. Effects of vitamin c or e on the pro-inflammatory cytokines, heat shock protein 70 and antioxidant status in broiler chicks under summer conditions. Asian-Australas J Anim Sci. 2014; 27: 749-756. [Medline] [CrossRef]

33. Song Z, Cheng K, Zhang L, Wang T. Dietary supplementation of enzymatically treated Artemisia annua could alleviate the intestinal inflammatory response in heat-stressed broilers. J Therm Biol. 2017; 69: 184-190. [Medline] [CrossRef]

34. Yun SH, Moon YS, Sohn SH, Jang IS. Effects of cyclic heat stress or vitamin $\mathrm{C}$ supplementation during cyclic heat stress on HSP70, inflammatory cytokines, and the antioxidant defense system in Sprague Dawley rats. Exp Anim. 2012; 61: 543-553. [Medline] [CrossRef]

35. Liu P, Piao XS, Kim SW, Wang L, Shen YB, Lee HS, et al. Effects of chito-oligosaccharide supplementation on the growth performance, nutrient digestibility, intestinal morphology, and fecal shedding of Escherichia coli and Lactobacillus in wean- ing pigs. J Anim Sci. 2008; 86: 2609-2618. [Medline] [CrossRef]

36. Pearce SC, Mani V, Weber TE, Rhoads RP, Patience JF, Baumgard LH, et al. Heat stress and reduced plane of nutrition decreases intestinal integrity and function in pigs. J Anim Sci. 2013; 91: 5183-5193. [Medline] [CrossRef]

37. Mourao JL, Pinheiro V, Alves A, Guedes CM, Pinto L, Saavedra MJ, et al. Effect of mannan oligosaccharides on the performance, intestinal morphology and cecal fermentation of fattening rabbits. Anim Feed Sci Technol. 2006; 126: 107-120. [CrossRef]

38. Yang CM, Ferket PR, Hong QH, Zhou J, Cao GT, Zhou L, et al. Effect of chito-oligosaccharide on growth performance, intestinal barrier function, intestinal morphology and cecal microflora in weaned pigs. J Anim Sci. 2012; 90: 2671-2676. [Medline] [CrossRef]

39. Zhu LH, Zhao KL, Chen XL, Xu JX. Impact of weaning and an antioxidant blend on intestinal barrier function and antioxidant status in pigs. J Anim Sci. 2012; 90: 2581-2589. [Medline] [CrossRef]

40. Naveed M, Phil L, Sohail M, Hasnat M, Baig MMFA, Ihsan $\mathrm{AU}$, et al. Chitosan oligosaccharide (COS): An overview. Int J Biol Macromol. 2019; 129: 827-843. [Medline] [CrossRef]

41. Wang Y, Wang Y, Wang B, Mei X, Jiang S, Li W. Protocatechuic acid improved growth performance, meat quality, and intestinal health of Chinese yellow-feathered broilers. Poult Sci. 2019; 98: 3138-3149. [Medline] [CrossRef]

42. Byun EB, Sung NY, Byun EH, Song DS, Kim JK, Park JH, et al. The procyanidin trimer $\mathrm{C} 1$ inhibits LPS-induced MAPK and NF- $\mathrm{KB}$ signaling through TLR4 in macrophages. Int Immunopharmacol. 2013; 15: 450-456. [Medline] [CrossRef]

43. Dou W, Zhang J, Sun A, Zhang E, Ding L, Mukherjee S, et al. Protective effect of naringenin against experimental colitis via suppression of Toll-like receptor $4 / \mathrm{NF}-\mathrm{kB}$ signalling. $\mathrm{Br} \mathrm{J}$ Nutr. 2013; 110: 599-608. [Medline] [CrossRef]

44. Qi S, Xin Y, Guo Y, Diao Y, Kou X, Luo L, et al. Ampelopsin reduces endotoxic inflammation via repressing ROS-mediated activation of PI3K/Akt/NF- $\mathrm{KB}$ signaling pathways. Int Immunopharmacol. 2012; 12: 278-287. [Medline] [CrossRef]

45. Xavier RJ, Podolsky DK. Unravelling the pathogenesis of inflammatory bowel disease. Nature. 2007; 448: 427-434. [Medline] [CrossRef]

46. Akbari P, Braber S, Alizadeh A, Verheijden KA, Schoterman $\mathrm{MH}$, Kraneveld AD, et al. Galacto-oligosaccharides protect the intestinal barrier by maintaining the tight junction network and modulating the inflammatory responses after a challenge with the mycotoxin deoxynivalenol in human Caco-2 cell monolayers and B6C3F1 mice. J Nutr. 2015; 145: 1604-1613. [Medline] [CrossRef]

47. Dann SM, Spehlmann ME, Hammond DC, Iimura M, Hase K, Choi LJ, et al. IL-6-dependent mucosal protection prevents establishment of a microbial niche for attaching/effacing lesionforming enteric bacterial pathogens. J Immunol. 2008; 180: 6816-6826. [Medline] [CrossRef] 